\title{
PERFORMANCE ANALYSIS OF A MODIFIED PNEUMATIC SEPARATOR FOR COWPEAS
}

\author{
O. E. Similowo, O. T. Araromi and O. O. Adesanya \\ Department of Mechanical Engineering, \\ University of Ibadan, Nigeria.
}

\begin{abstract}
In this work, modifications have been done on a prototype pneumatic separator to improve its efficiency. The effects of the modifications were studied by carrying out performance test analyses on the two blowers and reciprocating sieve mechanism which make up the critical components of the separating machine. The variations in the feed weights of the sieve were analysed to determine the best and most effective screening process. Also, the best and least tilt angles of the blowers were considered to determine the best and least blowing processes to clean the beans. The results of analyses showed that for a feed weight of $3.0 \mathrm{~kg}$ the sieving process attained its best efficiency of $50.2 \%$. The maximum efficiency of $79.2 \%$ for the first pneumatic separator was obtained at a tilt angle of $30^{\circ}$, while a maximum of $77.7 \%$ was obtained for the second separator at $0^{\circ}$ tilt angle. An overall efficiency of $77 \%$ was estimated for the modified pneumatic separator.
\end{abstract}

Keywords: - Pneumatic Separator; Design-Modifications; Performance-Analyses

\section{INTRODUCTION}

The tedium and stress involved in the manual processing and cleaning of large amount of grains prior to consumption within a given time limit has made the continual design and performance studies of alternative mechanical methods necessary. Subsequently, many works are been carried out on the removal of unwanted materials.

Earlier works include those of Sullivan (1970) and Lawton (1980) who studied vibrating screens and gravity tables respectively as means of separating grains from impurities. Also, Koya and Adekoya (1994) looked critically at some physical and aerodynamic properties relevant in de-stoning some grains. The outcome of the work and the principle of terminal velocity have been applied to the design of the separators carried out in this present work. However, in more recent times, (Dabor, unpublished); (Aigbokchai and Awomolo, unpublished) produced the first design of the pneumatic separator discussed in this paper. Other modifications were further done by (Araromi and Adesanya, unpublished). 
The Horizontal inertia-drive vibrating screen and the chaff aspirator are examples of post-harvest machines operating on the principles of vibration and gravity mentioned earlier developed over the years. However in this work a specified separator for cowpeas only to be used after the application of post-harvest separators prior to final home consumption on a larger scale has been developed. The modifications of the prototype carried out in this work aims at improving its efficiency. They include alteration of framework; inclusion of screening mechanisms; change of less efficient parts and proper surface finish to enhance attractiveness and value.

The performance analyses done in this work is an improvement over the previous due to the modifications made and more so the inclusion of the screening test which was not carried out in the previous works. Hence two major tests were carried out in the present performance analyses namely; the screen test and the pneumatic tests. Improvement and continuous work on the separators will eventually produce the optimum cleaning required for cowpea before home consumption

The overall objective of this work is to further reduce the boredom and tedium associated with large scale cleaning of cowpeas prior to final consumption. Specifically, it is to improve the efficiency of an existing pneumatic separator (Simolowo et al., 2004) by (i) introducing some design modifications on the existing prototype machine (ii) carrying out performance analyses on the modified pneumatic separator.

\section{DESCRIPTION AND FUNCTIONS OF MODIFIED MACHINE ELEMENTS}

The description of the prototype machine had earlier been presented in the preliminary works (Simolowo et al., 2004). The newly added parts are described with reference to the isometric view of the newly modified separating machine shown in Fig.1.
The modified frame that was designed with dimensions $800 \mathrm{~mm}$ by $550 \mathrm{~mm}$ and height of $1320 \mathrm{~mm}$ accommodates the shaker sieve, inclined plate and shaker mechanism. The cam converts rotary motion from pulley to translation motion in the sieve. It was constructed graphically to precision using mild steel flat bar of length $340 \mathrm{~mm}$, width $17 \mathrm{~mm}$ and thickness $30 \mathrm{~mm}$. The shakersieve serves as the flat face follower for the cam. The function of the shaker sieve is to receive the mix, agitate it and allow its passage to the inclined plate via its holes. It was constructed with mild steel sheet gauge $16 \mathrm{~mm}$ with dimensions $636 \mathrm{~mm}$ by $430 \mathrm{~mm}$ by $70 \mathrm{~mm}$ and consists of $8 \mathrm{~mm}$ drilled holes.

The included return spring returns the sieve after the required amplitude is reached by the rise of the cam. It was welded to the frame and has dimensions of $50 \mathrm{~mm} \times 30 \mathrm{~mm} \times 2 \mathrm{~mm}$. The inclined plate is $646 \mathrm{~mm} \times 430 \mathrm{~mm}$ and is inclined at $8^{\circ}$ to allow smooth rolling down of the cowpeas and ensure that the mix fall in front of the line of air flow. The grain collector is a rectangular tray made from mild steel sheet gauge $16 \mathrm{~mm}$. It is $70 \mathrm{~mm} \times 310 \mathrm{~mm} \times 160 \mathrm{~mm}$ and demarcated to separate the stones from mixing with the cleaned beans. The pulley incorporated into this modification is employed both for transmitting motion to the shaft in the shaker mechanism as well as reducing the speed of the cam. It was fabricated by coiling a mild steel rod $620 \mathrm{~mm}$ into circular shape and grooved to a depth $15 \mathrm{~mm}$. The pulley diameter is $350 \mathrm{~mm}$ and $20 \mathrm{~mm}$ thick to accommodate the fan belt.

\section{DESIGN OF MODIFIED MACHINE COMPONENTS}

In line with the earlier mentioned objectives of modifying an existing pneumatic cowpea separator as shown in Fig. 1, basic design principles are given only for modified parts in this section because considerations have been given to other existing parts in the prototype design of the equipment (Simolowo et al., 2004). 


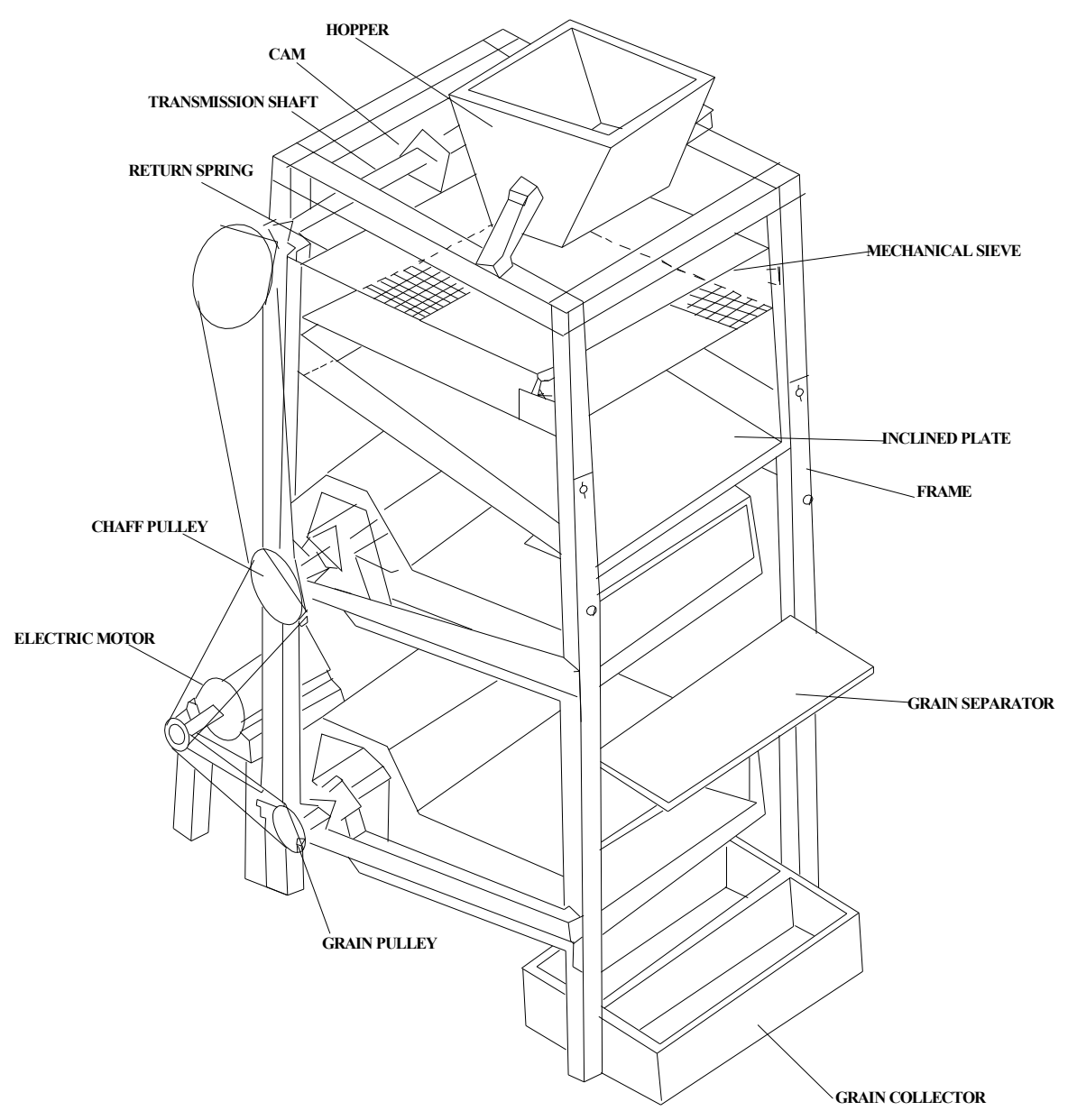

Fig. 1: THE ISOMETRIC VIEW OF MODIFIED BEAN / PARTICLE SEPARATING MACHINE

\section{Design of Cam Follower Mechanisms}

In the design of the complete cam/follower shaker mechanism introduced into the separator, five major sub-components are considered, namely; the cam profile, follower face width, angle of repose of inclined plane, return spring and shaker mechanism.

Cam Profile: - The following design criteria were used in the graphical design of the cam profile shown in figure 3: (i) the maximum displacement of the cam in contact with the shaker was taken as $30 \mathrm{~mm}$ for optimum agitation, (ii) a two-motion (Rise-Fall) profile was employed for smooth shaking of the sieve and (iii) the diameter of the offset hole in the cam was taken as $25 \mathrm{~mm}$ to make a tight fitting for the driver shaft

Face Width of Follower: - This represents the height of the shaker inclined plate in contact with 

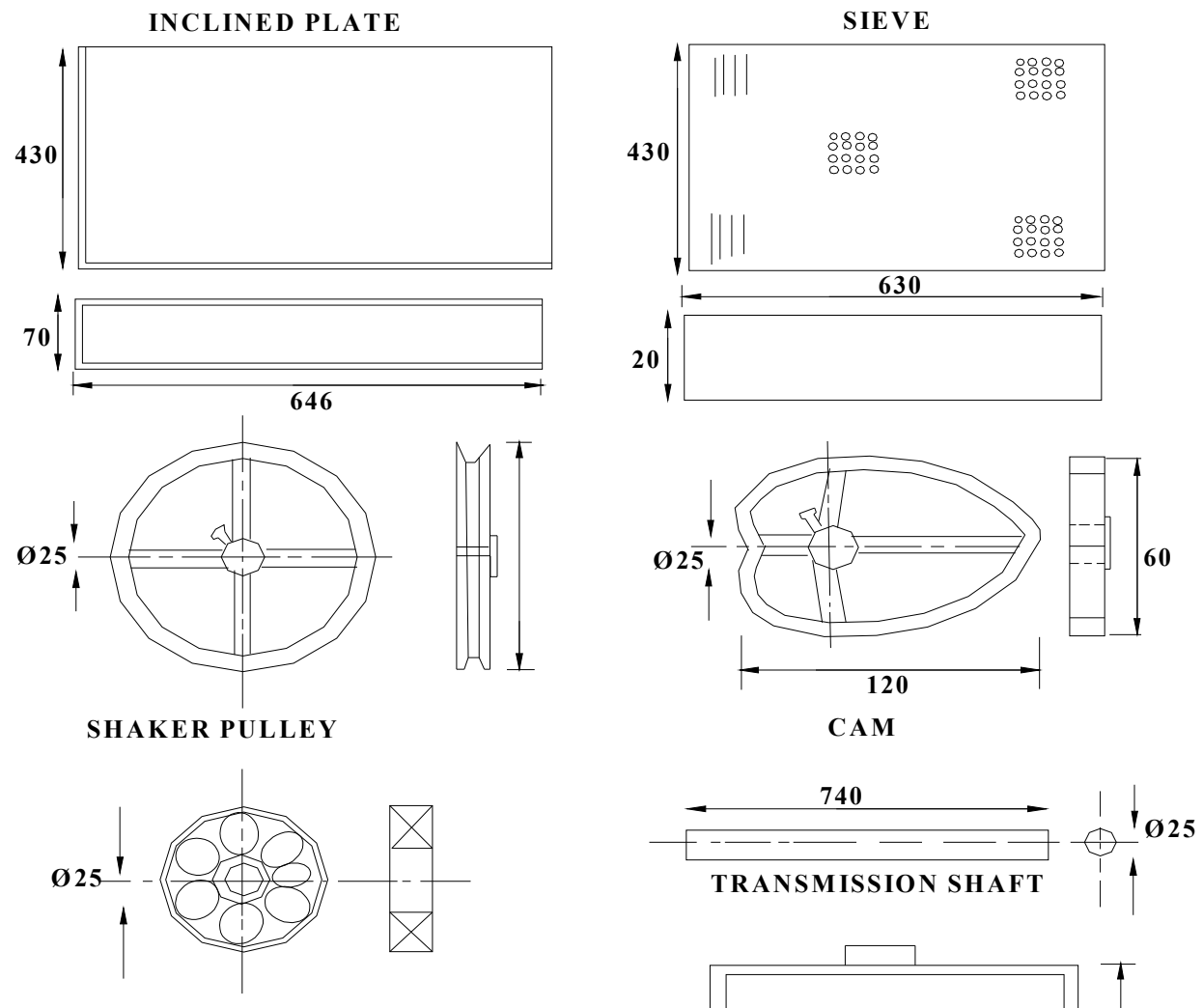

BALL BEARING
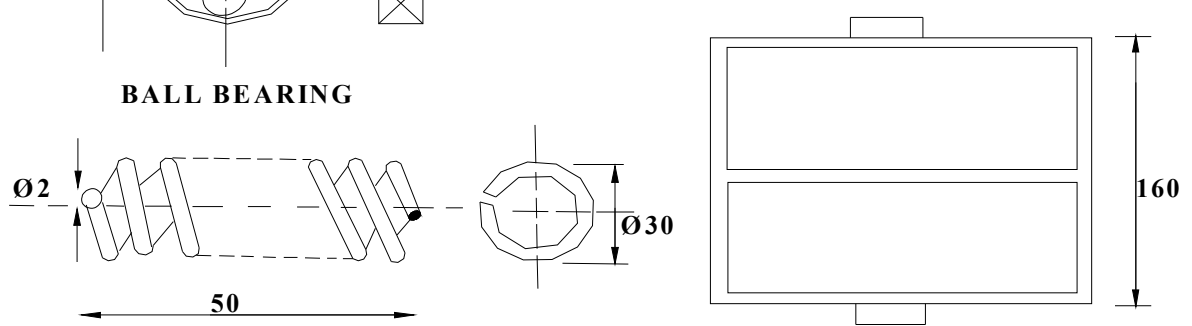

RETURN SPRING
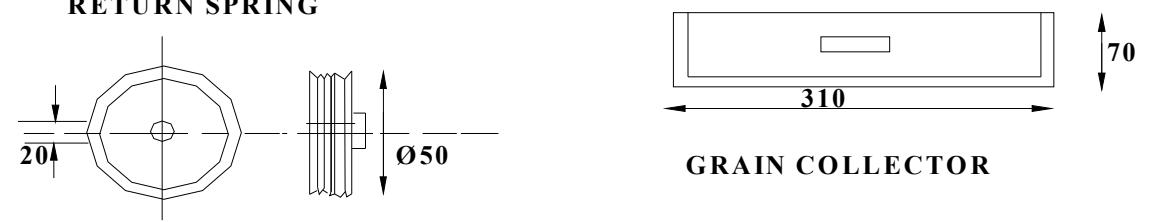

GRAIN COLLECTOR

ELECTRIC MOTOR PULLEY

Fig. 2: Components Parts of the Modifications Incorporated

134 Journal of Science and Technology, Vol. 27, No. 3, December 2007 


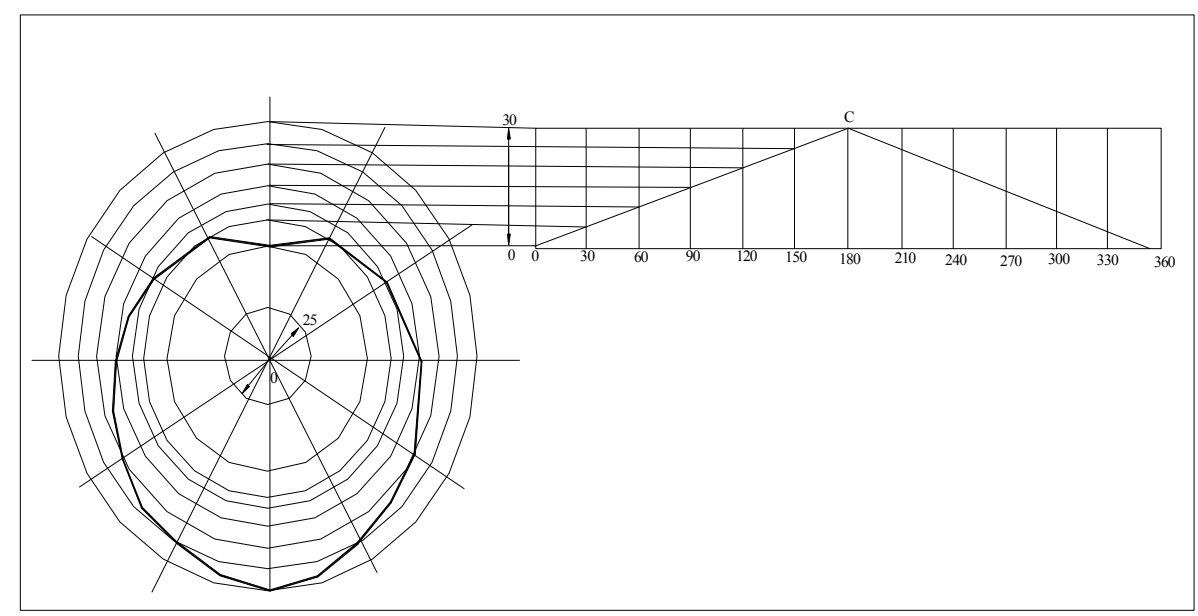

Fig. 3: GRAPHICAL DESIGN OF CAM PROFILE

the cam. It was determined based on three critical considerations: (i) maximum dimension across the oval shaped cam after its design measured to be $60 \mathrm{~mm}$ (figure 3), (ii) determined height for the shaker to accommodate enough cowpeas. Having known the shaker length $(0.636 \mathrm{~m})$, width $(0.43 \mathrm{~m})$ and optimum volume of grain $0.02 \mathrm{~m}^{3}$ this height was determined, (iii) the required Face width must be equal to or greater than values obtained in (i) and (ii) to maintain constant contact between the inclined shaker plate and cam without the grains falling off.

Return Spring Strength: - This is determined by considering the shear stress $(\tau)$; Store energy $\left(\mathrm{U}_{\mathrm{s}}\right)$ and maximum allowable stress $\left(\mathrm{S}_{\mathrm{s}} \max \right)$. Equations (1), (4), (6) are used to determine these three parameters respectively (Allen et al, 2002). Where $\mathrm{F}$ is axial load on spring; $\mathrm{K}$ is Wahl factor given as equation (2); $\mathrm{D}$ is mean diameter of spring coil; $\mathrm{d}$ is diameter of wire; $\mathrm{C}$ is the spring index given as equation (3); y the axial deflection is given as (5); $\mathrm{G}$ is the modulus of rigidity and $n$ is the number of spring turns

$$
\begin{aligned}
& \tau=\frac{K 8 F D}{\pi d^{3}} \\
& k=\frac{4 C-1}{4 C-4}+\frac{0.615}{C} \\
& C=\frac{D}{d} \\
& \mathrm{U}_{\mathrm{s}}=1 / 2 F y \\
& y=\frac{8 E D{ }^{3} n}{d^{4} G} \\
& S_{S(\max )} \frac{K_{s} 8 D F}{\pi d^{3}} \max
\end{aligned}
$$

Where $F_{\max }=2 \mathrm{~F}$ for continuous loading considered in this design and $\mathrm{K}_{\mathrm{s}}$ is known as the shear stress sub factors given as equation (7)

$$
K_{s}=1+\frac{0.5}{C}
$$




\section{Design of Shaker Sieve}

The critical design parameter for the shaker sieve is the diameter of sieve holes. The concept of equilibrium moisture content of the bean was employed in this work. The radius of the bean $\left(\mathrm{r}_{\mathrm{b}}\right)$ was calculated using equation (8) (Fellow,1993). The volume of grain $\left(\mathrm{V}_{\mathrm{b}}\right)$ was determined by equation (9) while $r_{b}$ is the given bulk density of grain.

$$
\begin{aligned}
& V_{b}=\frac{4}{3} \pi r_{b} b^{3} \\
& \rho_{b}=\frac{M_{b}}{V_{b}}
\end{aligned}
$$

$M_{b}$ is the mass of grain, which was obtained by the mole concept for amino acids and glucose in the bean considered for analysis.

\section{Design of Shaker Pulley}

In this paper, consideration was given to the chaff pulley diameter, the speed of chaff pulley and the diameter of shaker pulley. All other related aspects of design for the shaker pulley have been considered in earlier works.

Shaker Diameter: - The chaff pulley speed $\mathrm{N}_{\mathrm{c}}$ was calculated using equation (10); Ns the speed of shaker pulley is obtained using equation (11) and $D_{s}$ the diameter of shaker is calculated by equation 12

$\mathrm{N}_{M}$ and $\mathrm{D}_{\mathrm{M}}$ are the given speed and diameter of electric motor respectively. Also the diameter of

$\mathrm{N}_{\mathrm{M}} \mathrm{D}_{\mathrm{M}}=\mathrm{N}_{\mathrm{c}} \mathrm{D}_{\mathrm{c}}$.

$$
\mathrm{N}_{s}=1 / 3 N_{c}
$$

$\mathrm{N}_{\mathrm{c}} \mathrm{D}_{\mathrm{c}=} \mathrm{N}_{\mathrm{s}} \mathrm{D}_{\mathrm{s}}$

the chaff $D_{c}$ was obtained by applying equation 13 (Osborne, 1996; Koya, 1994). In this equation $d_{2}$ is diameter of fan impeller from center, $b_{2}$ is axial width of impeller, $D_{m}$ is diameter of electric motor driving pulley; $\mathrm{N}_{\mathrm{m}}$ is speed of electric motor and $A_{o}$ is cross sectional area of fan outlet. A more detailed and illustrative design has been presented in earlier works (Simolowo et al, 2004)

$$
V_{T}=\frac{0.4 \pi d_{2} b_{2} D_{m} N_{m}}{60 A_{o} D_{c}}
$$

Furthermore, the speed of the shaft was analysed based on the representative free body diagrams of Figure 4 depicting the forced linear vibration experienced by the mass $\mathrm{m}$ (sieve) acted upon by a restoring force $\mathrm{F}$ (spring) thereby causing a unit displacement $\mathrm{x}$ from equilibrium. The second order displacement $\ddot{x}(t)$ the linear velocity

$\dot{x}(t)$ and the speed of shaft $\mathrm{N}_{\mathrm{s}}$ are calculated us

$$
\begin{array}{r}
F=M \ddot{x}(t) \\
\dot{x}=\int \ddot{x}(t) d x \\
\dot{x}(t)=\frac{2 \pi N_{s} R_{s}}{60}
\end{array}
$$

Where $\mathrm{M}$ is total mass of sieve obtained by density- volume relationship and $R_{s}$ is radius of shaft pulley.

\section{Determination of shaft Diameter for shaker pulley.}

The diameter D for the transmission shaft of the shaker pulley is determined using the ASME code equation given in equation (17). The combined shock and fatigue factors for bending $\left(\mathrm{K}_{\mathrm{b}}\right)$ and torsion $\left(\mathrm{K}_{\mathrm{T}}\right)$ are given as 2.0 and 1.5 respectively

$$
\begin{gathered}
{\left[\frac{16}{\pi s} \sqrt{\left(K_{b} M_{b}\right)^{2}+\left(K_{T} M_{T}\right)^{2}}\right]^{\frac{1}{3}} \ldots} \\
M_{T}=\frac{9550 X K W}{N_{s}} .
\end{gathered}
$$

136 Journal of Science and Technology, Vol. 27, No. 3, December 2007 


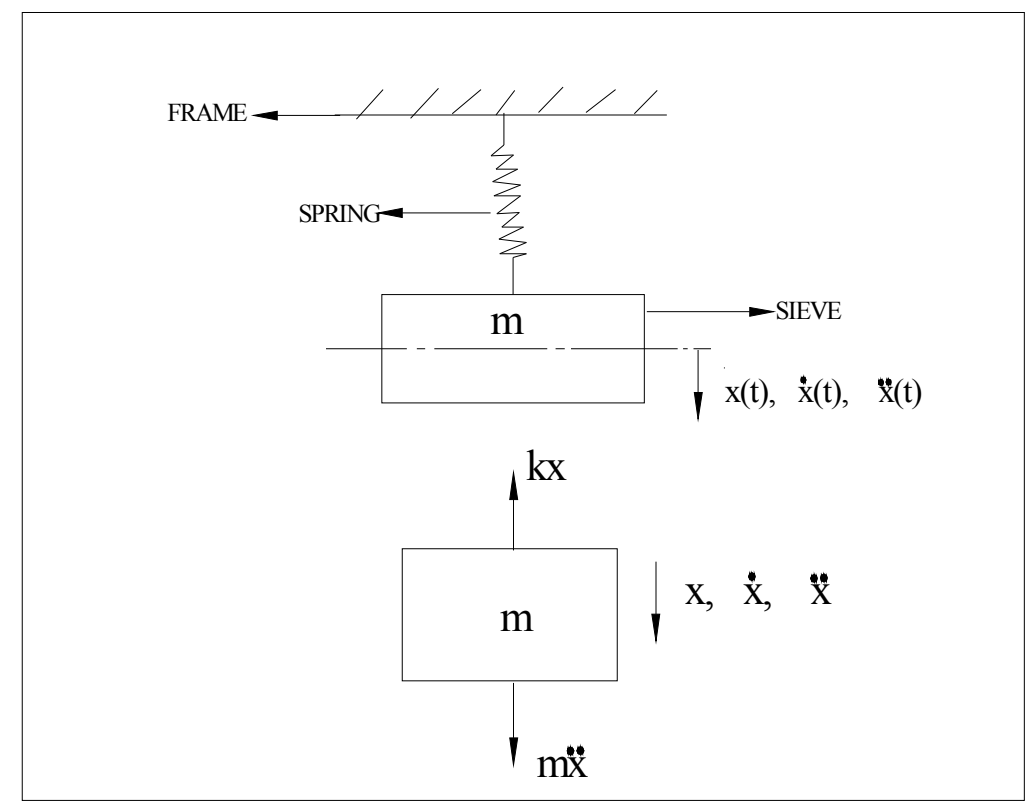

Fig. 4: FREE BODY DIAGRAM

The shaft is designed based on the torsional moment $\mathrm{M}_{\mathrm{T}}$ given by equation (18) and maximum bending moment $\mathrm{M}_{\mathrm{b}}$ which was obtained by analysis of vertical and horizontal loadings on the shaft

\section{Selection of Bearing Size for Shaker Pulley}

The ISO equation for basic rating life for ball bearing given as equation (19); (Allen and Alfred, 2002) was used. $L_{10}$ is the basic rating life in million revolutions; $\mathrm{C}$ is the basic dynamic load rating which is recommended to be a life of 20,000-30,000 hours for machine in general, where machines are fully utilized for 8 hours. The exponential life of 3 was applied in design while the equivalent dynamic load $\mathrm{P}$ was calculated using equation (20). The radial and safety factors applicable to design are given as 1.0 for both. The thrust load $\mathrm{F}_{\mathrm{a}}$ and thrust factor $\mathrm{Y}$ are taken to be zero because no thrust loading exists on the shaker shaft. Radial load $F_{r}$ is present and was determined by analyses of bearing reactions for vertical and horizontal load

$$
\begin{aligned}
& L_{10}=\left[\frac{C}{P}\right]^{e} \ldots \ldots \ldots \ldots \ldots \ldots \ldots \ldots \ldots \ldots \ldots \text { (19) } \\
& P=X V F_{R}+Y F_{A}
\end{aligned}
$$

\section{METHODOLOGY OF PERFORMANCE TEST \\ ANALYSIS}

The objective of the test was to carry out performance analyses of the sieve (screening test) and blowers (pneumatic tests) of the bean particle-separating machine.

\section{Methodology of performance analysis}

Screening test:- The mix i.e. the mixture of beans, chaff and stones were weighed and recorded. The mixes at different feed weights were introduced at a time interval of 120 seconds. The 
screened mixes collected at the inclined plate were weighed for each mix introduced. Efficiencies were then obtained for various feed weight of the mix introduced.

Pneumatic test for fan blowers: - The partially cleaned mix collected and weighed earlier was separated manually i.e. by hand picking and the mix were weighed separately and recorded. This was then introduced into line of airflow of the first blower via the inclined plane at various tilt angles $\left(0^{\circ}, 10^{\circ}, 20^{\circ}, 30^{\circ}\right)$. The same process was carried out for the second blower. Efficiencies were obtained for the various tilt angles of the two blowers.

The efficiencies of the screening processes $\left(\mathrm{Eff}_{\mathrm{s}}\right)$ were determined by equation (21) while those for the pneumatic tests for $1^{\text {st }}$ and $2^{\text {nd }}$ blowers were done with equations (22) and (23) respectively. The overall efficiency of the machine was obtained using equation (24)

$$
\begin{aligned}
& \operatorname{Eff}(\%)=\frac{W m(B F)-W m(A F)}{W m(B F)} \times 100 \\
& \operatorname{Eff}_{\mathrm{b} 1}(\%)=\frac{W m(A F)-W c(A F)}{W m(B F)} \times 100 \\
& \operatorname{Eff}_{\mathrm{b} 2}(\%)=\frac{W m(A F)-(W c(A F)+W s(A F))}{W m(B F)} \times 100 \\
& \text { Eff. }_{\text {ovcrall }}(\%)=\frac{W m h(B F)-(W m 2(A F)}{W m h(B F)} \times 100
\end{aligned}
$$

Where; Wm (Bf) is Weight of mix before separation; Wm (Af) is Weight of mix after separation; $\mathrm{Wc}(\mathrm{Bf})$ is Weight of chaff before separation; Wc (Af) is Weight of chaff after separation; Ws (Bf) is Weight of stone before separation; Ws (Af) is Weight of stone after separation; Wmh (BF) is weight of the mix at the hopper before separation $(\mathrm{N})$; Wm2 (AF) is Weight of the mix at 2nd Fan after separation (N)

\section{RESULTS AND DISCUSSION}

Efficiency of the Screening Process

Figure 5 shows the efficiencies for the screening mechanism test presented in table (1). At feed
Fig. 5: -Efficiencies of screening processes for different feed weights

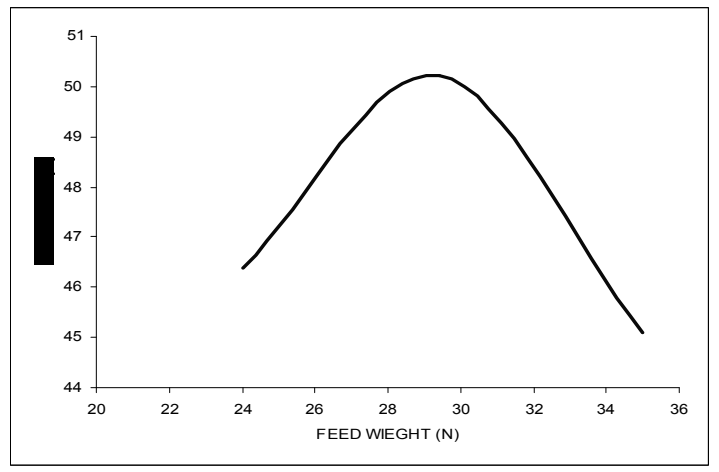

weight of $29.43 \mathrm{~N}$ i.e. $3.0 \mathrm{~kg}$, the sieving process attained its best efficiency of $50.2 \%$ for the $2 \mathrm{nd}$ trial. The sieve is supposed to partially screen particles bigger in size than the beans.

\section{Efficiency of the First Pneumatic Process}

Shown in Figure 6 are the efficiencies for the performance test results for the first pneumatic separator presented in table 2 . The weight of the mix considered for a free fall in this analysis is the weight of mix after the screening process with the highest efficiency i.e. $14.72 \mathrm{~N}(1.5 \mathrm{~kg})$. Different tilt angles $0^{\circ}, 10^{\circ}$ and $30^{\circ}$ were taken for the test.

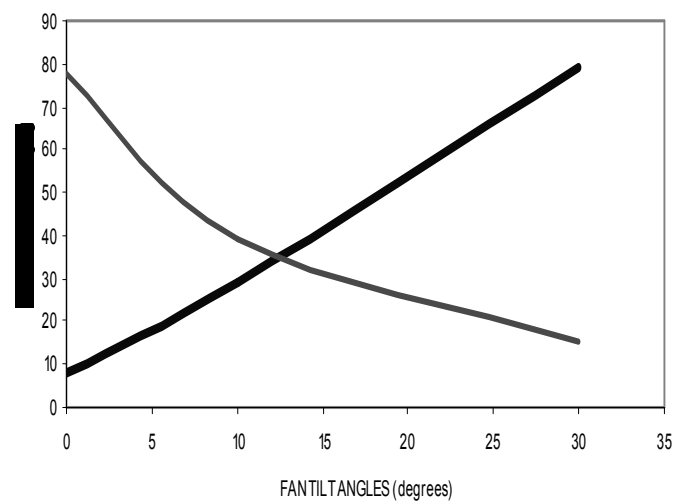

Fig. 6: Efficiencies of Blowers at different tilt angles

138 Journal of Science and Technology, Vol. 27, No. 3, December 2007 
The first blower is expected to expel the chaff from the mix in the line of free fall but not to remove the beans. At $0^{\circ}$ tilt angle, the intensity of the air velocity was too much to expel not only the chaff but also the beans from the line of free fall. At increase tilt angle of $30^{\circ}$, the intensity of the air velocity was reduced so that only the chaff was blown away and the beans was allowed to continue to fall freely to the line of airflow of the second blower. The tilt angle $30^{\circ}$ was consequently adapted for the unit design.

\section{Table 1: Performance tests results for} screening mechanism

\begin{tabular}{cccc}
\hline Feed Weight $(\mathrm{N})$ & $1^{\text {st }}$ Test & $2^{\text {nd }}$ Test & $3^{\text {rd }}$ Test \\
\hline Wm (BF) & 24.53 & 29.43 & 34.34 \\
Wm (AF) & 13.20 & 14.72 & 18.64 \\
\hline
\end{tabular}

Efficiency of the Second Pneumatic Process Shown in Figure 6 also are the efficiencies for the performance test results for the second pneumatic separator presented in table 3 . The pneumatically separated mix from the first blower was allowed to fall freely on the line of airflow of the second blower. Different tilt angles $0^{\circ}, 10^{\circ}$ and $30^{\circ}$ were also considered for the test. The feed weight considered for this test was the weight of the mix after the chaff had been separated at the best tilt angle with highest efficiency i.e. $11.65 \mathrm{~N}(1.2 \mathrm{~kg})$.

The second fan was designed to expel the beans from the mix of free fall only. At $0^{\circ}$ tilt angle, the intensity of the air velocity was enough to blow away the beans from the mix. Increase in tilt angle reveals that the intensity of the air velocity was not enough to expel the beans therefore the tilt angle $0^{\circ}$ was consequently adapted to design the second blower of the unit.

\section{Overall Efficiency of the Machine}

The weight considered for the overall efficiency of the machine was that of the experiment with best efficiency at the sieve, and best tilt angles for the chaff and bean blowers. Equation (24) was used in determining this efficiency as $70 \%$. The Efficiency recorded from the performance test analysis showed that the machine could be em-

Table 2: Performance tests results for $1^{\text {st }}$ pneumatic separator

\begin{tabular}{|c|c|c|c|c|c|c|c|c|c|c|}
\hline \multirow[b]{2}{*}{$\begin{array}{c}\text { FAN } \\
\text { TILT } \\
\text { ANGLE }\end{array}$} & \multicolumn{2}{|c|}{ Feed Weight } & \multicolumn{2}{|c|}{$1^{\text {st }}$ Test } & \multicolumn{2}{|c|}{$2^{\text {nd }}$ Test } & \multicolumn{2}{|c|}{$3^{\text {rd }}$ Test } & \multicolumn{2}{|c|}{ Average } \\
\hline & $\begin{array}{l}\text { Wm } \\
\text { Bf } \\
(\mathrm{N})\end{array}$ & $\begin{array}{l}\text { We } \\
\text { (Bf) } \\
(\mathrm{N})\end{array}$ & $\begin{array}{c}\text { Wm } \\
\text { Af } \\
(\mathbf{N})\end{array}$ & $\begin{array}{l}\text { We } \\
\text { (Af) } \\
(\mathbf{N})\end{array}$ & $\begin{array}{c}\text { Wb } \\
(\mathbf{A f}) \\
(\mathbf{N})\end{array}$ & $\begin{array}{l}\text { We } \\
\text { (Af) } \\
(\mathbf{N})\end{array}$ & $\begin{array}{c}\text { Wb } \\
(\text { Af) } \\
(\mathbf{N})\end{array}$ & $\begin{array}{c}\text { Wc } \\
\text { (Af) } \\
(\mathbf{N})\end{array}$ & $\begin{array}{c}\text { Wb } \\
(\mathbf{A f}) \\
(\mathbf{N})\end{array}$ & $\begin{array}{r}\text { We } \\
\text { (Af) } \\
\text { (N) }\end{array}$ \\
\hline $0^{\circ}$ & 14.72 & 2.94 & 1.18 & 0 & 1.18 & 0 & 1.18 & 0 & 1.18 & 0 \\
\hline $10^{\circ}$ & 14.72 & 2.94 & 4.12 & 0 & 4.12 & 0 & 4.12 & 0 & 4.12 & 0 \\
\hline $30^{\circ}$ & 14.72 & 2.94 & 11.65 & 0 & 11.65 & 0 & 11.65 & 0 & 11.65 & 0 \\
\hline
\end{tabular}

Table 3: Performance tests results for $2^{\text {nd }}$ pneumatic separator

\begin{tabular}{|c|c|c|c|c|c|c|c|c|c|c|c|c|}
\hline \multirow[b]{2}{*}{$\begin{array}{c}\text { FAN } \\
\text { TILT } \\
\text { ANGLE }\end{array}$} & \multicolumn{3}{|c|}{$1^{\text {st }}$ Test } & \multicolumn{3}{|c|}{$2^{\text {nd }}$ Test } & \multicolumn{3}{|c|}{$3^{\text {rd }}$ Test } & \multicolumn{3}{|c|}{ Average } \\
\hline & $\begin{array}{l}\text { Wm } \\
\text { (Af) } \\
\text { (N) }\end{array}$ & $\begin{array}{l}\text { Wc } \\
\text { (Af) } \\
\text { (N) }\end{array}$ & $\begin{array}{l}\text { Ws } \\
\text { (Af) } \\
\text { (N) }\end{array}$ & $\begin{array}{l}\text { Wm } \\
\text { (Af) } \\
\text { (N) }\end{array}$ & $\begin{array}{l}\text { Wc } \\
\text { (Af) } \\
\text { (N) }\end{array}$ & $\begin{array}{l}\text { Ws } \\
\text { (Af) } \\
\text { (N) }\end{array}$ & $\begin{array}{l}\text { Wm } \\
\text { (Af) } \\
\text { (N) }\end{array}$ & $\begin{array}{l}\text { We } \\
\text { (Af) } \\
\text { (N) }\end{array}$ & $\begin{array}{l}\text { Ws } \\
\text { (Af) } \\
\text { (N) }\end{array}$ & $\begin{array}{l}\text { Wm } \\
\text { (Af) } \\
\text { (N) }\end{array}$ & $\begin{array}{l}\text { Wc } \\
\text { (Af) } \\
\text { (N) }\end{array}$ & $\begin{array}{l}\text { Ws } \\
\text { (Af) } \\
\text { (N) }\end{array}$ \\
\hline $0^{\circ}$ & 9.05 & 0 & 0 & 9.05 & 0 & 0 & 9.05 & 0 & 0 & 9.05 & 0 & 0 \\
\hline $10^{\circ}$ & 4.55 & 0 & 0 & 4.55 & 0 & 0 & 4.55 & 0 & 0 & 4.55 & 0 & 0 \\
\hline $30^{\circ}$ & 1.80 & 0 & 0 & 1.80 & 0 & 0 & 1.80 & 0 & 0 & 1.80 & 0 & 0 \\
\hline
\end{tabular}


ployed to ensure proper separation of beans from unwanted materials.

\section{CONCLUSION AND RECCOMENDATION}

The efficiency of the existing pneumatic separator has been increased due to the incorporation of some other machine components. An efficiency of $50 \%$ was obtained for the screening and shaker mechanism of the separator for a feed weight of $29.43 \mathrm{~N}$ i.e. $3.0 \mathrm{~kg}$. Efficiencies of $79.2 \%$ at $30^{\circ}$ tilt angle and $77.7 \%$ at $0^{\circ}$ tilt angle were also obtained for the first and second blowers respectively.

In summary, the results of analyses carried out in this work showed that lengthy manual process of beans cleaning and preparation prior to final large-scale consumption has been greatly reduced with the use of this modified separator.

The overall efficiency of $70 \%$ for the equipment shows that more improvements could be further made on the pneumatic separator. Also the use of multi-speed electric motors and different detachable sieves are recommended for the machine, thereby making it possible to clean different grains by regulating the speed of the motors.

\section{REFERENCES}

Allen, S.H., Alfred R.H., and Herman, G.L. (1982). Theory and Problems of Machine Design.

Singapore: McGraw-Hill Publishing Company.

Koya, O.A. and Adekoya, I.O. (1994). Some Physical and Aerodynamic Properties Relevant in

Destoning Some Grain Crops. Ife Journal of Technology, 4(2):35-40.

Lawton, P.J. (1980). Coefficient of friction for seria grains and various wall material agricultural products. 25:75-86. U.S.A: Pitman Publishing Inc.

Osborn, W.C. (1996). Fans. London: Pergamon Press.

Sullivan J.F. (1970). Applications in the seed, grain and milling industries. 13: 1-4. London Triples Dynamic Suctton Inc.

Simolowo, O.E., Dabor, S.E., Aigbokihai, S.O and Awomolo, A. (2004). Performance Analysis of Pneumatic Separators for a Beans Particle Separating Machine. The Nigerian Academic Forum. 6(3): 129-133.

140 Journal of Science and Technology, Vol. 27, No. 3, December 2007 